\title{
Ferritin level prospectively predicts hepatocarcinogenesis in patients with chronic hepatitis B virus infection
}

\author{
ZHENYUAN BIAN $^{1}$, HIE-WON HANN ${ }^{2}$, ZHONG YE $^{3}$, CHUN YIN $^{4}$, YANG WANG $^{1}$, \\ WAN FANG $^{4}$, SHAOGUI WAN ${ }^{5}$, CHUN WANG $^{3}$ and KAISHAN TAO ${ }^{1}$
}

${ }^{1}$ Department of Hepatobiliary Surgery, Xijing Hospital, Fourth Military Medical University, Xi'an, Shaanxi 710032, P.R. China; ${ }^{2}$ Division of Gastroenterology and Hepatology, Department of Medicine, Liver Disease Prevention Center; ${ }^{3}$ Division of Population Science, Department of Medical Oncology, Sidney Kimmel Cancer Center,

Thomas Jefferson University, Philadelphia, PA 19107, USA; ${ }^{4}$ State Key Laboratory of Cancer Biology and

Experimental Teaching Center of Basic Medicine, Fourth Military Medical University, Xi'an, Shaanxi 710032;

${ }^{5}$ Institute of Pharmacy, Pharmaceutical College of Henan University, Kaifeng, Henan 475004, P.R. China

Received February 23, 2018; Accepted May 24, 2018

DOI: $10.3892 / \mathrm{ol} .2018 .9099$

\begin{abstract}
Previous studies have detected a higher level of ferritin in patients with hepatocellular carcinoma (HCC), but a potential causal association between serum ferritin level and hepatocarcinogenesis remains to be clarified. Using a well-established prospective cohort and longitudinally collected serial blood samples, the association between baseline ferritin levels and HCC risk were evaluated in 1,152 patients infected with hepatitis B virus (HBV), a major risk factor for HCC. The association was assessed by Cox proportional hazards regression model using univariate and multivariate analyses and longitudinal analysis. It was demonstrated that HBV patients who developed HCC had a significantly higher baseline ferritin level than those who remained cancer-free (188.00 vs. $108.00 \mathrm{ng} / \mathrm{ml}, \mathrm{P}<0.0001)$. The patients with a high ferritin level $(\geq 200 \mathrm{ng} / \mathrm{ml})$ had 2.43-fold increased risk of HCC compared to those with lower ferritin levels [hazard ratio (HR), 2.43; 95\% confidence interval, 1.63-3.63]. A significant trend of increasing HRs along with elevated ferritin levels was observed ( $\mathrm{P}$ for trend $<0.0001)$. The association was still significant after multivariate adjustment. Incorporating ferritin into the $\alpha$-fetoprotein
\end{abstract}

Correspondence to: Dr Chun Wang, Division of Population Science, Department of Medical Oncology, Sidney Kimmel Cancer Center, Thomas Jefferson University, Suite 727, 1025 Walnut Street, Philadelphia, PA 19107, USA

E-mail: chun.wang@jefferson.edu

Dr Kaishan Tao, Department of Hepatobiliary Surgery, Xijing Hospital, Fourth Military Medical University, 169 Changle West Road, Xi'an, Shaanxi 710032, P.R. China

E-mail: taokaishan0686@163.com

Key words: ferritin, hepatocellular carcinoma, hepatitis B virus, risk, prospective
(AFP) model significantly improved the performance of HCC prediction (the area under the curve from 0.74 to 0.77 , $\mathrm{P}=0.003$ ). Longitudinal analysis showed that the average ferritin level in HBV patients who developed HCC was persistently higher than in those who were cancer-free during follow-up. HCC risk reached a peak at approximately the fifth year after baseline ferritin detection. Moreover, stratified analyses showed that the association was noted in both males and females, and was prominent in patients with a low AFP value. In short, serum ferritin level could independently predict the risk of HBV-related HCC and may have a complementary role in AFP-based HCC diagnosis. Future studies are warranted to validate these findings and test its clinical applicability in HCC prevention and management.

\section{Introduction}

Hepatocellular carcinoma (HCC) is the third leading cause of cancer-related death worldwide and a major cause of death in patients with cirrhosis (1). By the time HCC is detected, it has often reached an advanced stage for which there is no curative treatment. In order to identify HCC earlier, efforts have focused on patients with chronic hepatitis B virus (HBV) infection, which affects 350 million persons worldwide and is the most common risk factor for HCC (1). The ability to identify patients who are at high risk for HBV-related HCC would benefit the prevention and early detection of HCC.

Recent studies have indicated that measurement of ferritin, the major cellular storage protein for iron (2), may allow for such early detection of HCC. In vitro studies showed that iron induced increased ferritin synthesis by hepatoma cell lines and enhanced tumor cell growth $(3,4)$. Elevated serum ferritin was also associated with inflammation and liver diseases $(2,5,6)$. Moreover, ferritin that is synthesized by tumor cells may exert adverse effects on host immune responses and defense mechanisms (3). Population studies have clearly documented that HCC patients have a higher level of ferritin than healthy subjects or patients with other 
liver diseases (7-9), but retrospective studies cannot clarify whether the increased level is the cause or consequence of HCC because ferritin is also produced by the tumor cells. Meanwhile, very few studies have prospectively evaluated the relationship between serum ferritin level and HCC risk in HBV patients. A nested case-control study in Taiwan reported that 192 men who developed primary HCC and/or died of cancer had higher mean serum ferritin at the start of the study, compared to those who were alive and free of HCC at the date the case failed (developed HCC or died of cancer) (10). A study conducted in Korean patients with chronic hepatitis B and cirrhosis reported that males with sustained high serum ferritin levels had a high chance of developing HCC (5); however, in this study, only 162 patients (46 females) were included, ferritin levels were merely measured within the first 8 months, and covariates were not considered. We designed a prospective cohort study with more than 10-year follow-up and longitudinally collected serial blood samples from $\mathrm{HBV}$-infected patients in order to further clarify the association between baseline ferritin levels and HCC risk in $\mathrm{HBV}$-infected patients, and to explore the dynamic change of ferritin level and HCC risk over time.

\section{Subjects and methods}

Subjects. The subjects were identified from an ongoing clinic-based patient cohort that was established in 1988 (11). The patients were recruited when they visited the Liver Disease Prevention Center at Thomas Jefferson University Hospital for the treatment of chronic HBV or HCV infection and liver diseases including cirrhosis, fibrosis, and/or HCC. There was no restriction on age, gender, and disease etiology for patient recruitment. Majority (>90\%) of the patients in the cohort were of Korean ancestry. The patients included in the current study met the following criteria: i) To eliminate the confounding effects from disease etiologies, patients had HBV infection only, without concomitant infection with HCV, HIV, or other viruses; ii) to minimize the confounding effects of population stratification and ethnic origin, patients were Korean Americans; iii) patients had developed primary rather than secondary HCC during follow-up; iv) patients were followed for at least 1 year, and during which time HCC did not develop; v) patients had both ferritin and $\alpha$-fetoprotein (AFP) values measured simultaneously at study entry; and vi) major demographic and clinical data were available, such as date of HCC diagnosis. This study was approved by the Institutional Review Board of Thomas Jefferson University. Written informed consent was obtained from each patient.

Data collection. Demographic and clinical data were obtained by reviewing medical charts and/or consulting the treating physicians. Related variables included age, gender, ethnicity, smoking status, drinking status, cirrhosis status, and family history of cancer. Ever smokers and drinkers were defined as previously (12). Liver cirrhosis and HCC were diagnosed by the combination of clinical diagnosis and imaging techniques (e.g., ultrasound, computed tomography, magnetic resonance imaging), complemented by blood markers (e.g., AFP) (11). Ferritin levels for each patient were detected at the initial visit, as well as at follow-up visits, with the intervals determined by the treating physicians.

Statistical analysis. SAS (version 9.4; SAS Institute, Inc., Cary, NC, USA) and Stata (version 12.0; StataCorp LP, College Station, TX, USA) software packages were used for data analyses. All statistical tests were two-sided, and a P-value of less than 0.05 was considered as the threshold of statistical significance. The clinical endpoint analyzed in this study was HCC development. Time to HCC development was defined as the date from the study entry to the date of HCC diagnosis or last follow-up. Patients who were free of HCC at the last follow-up date were censored for analysis. The patients were then divided into two, three, or four risk groups, according to the clinical cut-off of $200 \mathrm{ng} / \mathrm{ml}(2,13)$, or median/tertile/quartile of ferritin level in cancer-free $\mathrm{HBV}$ patients. The cumulative incidence of $\mathrm{HCC}$ in each risk group was plotted using the Nelson-Aalen method (14) and compared using the log-rank test. The association between ferritin level and HCC risk was evaluated using univariate and multivariate Cox proportional hazards regression model, adjusting for age, gender, smoking status, drinking status, cirrhosis, and family history of cancer. Because all patients received standard-of-care treatment based on the AASLD guidelines and adjustment of treatment did not affect the results, we did not include treatment in the multivariate adjustment in the current study. The proportional hazards assumption was validated using the test based on Schoenfeld residuals. The significance and strength of association was presented as hazard ratio (HR) with $95 \%$ confidence interval (CI). Discrimination accuracy for predicting the development of $\mathrm{HCC}$ was evaluated by constructing receiver operating characteristic (ROC) curves and calculating the area under the curve (AUC). Interactions between ferritin levels and other variables on HCC risk were assessed by adding an interaction term into the Cox regression model. Time-dependent effect of ferritin levels on HCC risk was analyzed using the flexible parametric survival model with a restricted cubic spline function (15). To better understand the dynamic change of ferritin during follow-up, we selected a sub-cohort of 461 patients whose ferritin level was detected $\geq 3$ times since the initial visit. The longitudinal trends of temporal changes in average ferritin levels were plotted by fitting a smoothing spline over time and compared between the patients who developed HCC and those who remained cancer-free during follow-up (16).

\section{Results}

Patient characteristics. A total of 1,152 HBV patients were included in this study, and among them, 96 (8.3\%) patients developed early-stage HCC during follow-up. The patient characteristics are summarized in Table I. The mean age of patients at enrollment was 43.6 years old (age range: 18.7-77.8 years). The majority of patients were males $(66.1 \%$, sex ratio: 1.95$)$, never smokers $(59.7 \%)$, never drinkers $(56.1 \%)$, without cirrhosis $(71.8 \%)$ or a family history of cancer $(67.4 \%)$. As expected, HCC risk was significantly increased among older patients $(\mathrm{HR}=2.23,95 \% \mathrm{CI}, 1.36-3.65)$, males $(\mathrm{HR}=1.88$, 95\% CI, 1.01-3.47), ever smokers (HR=2.47, 95\% CI, 1.39-4.38), 
Table I. Characteristics of the study population.

\begin{tabular}{|c|c|c|c|c|c|c|}
\hline \multirow[b]{2}{*}{ Variables } & \multirow[b]{2}{*}{$\begin{array}{c}\text { Total HBV } \\
\text { patients, no. }(\%)\end{array}$} & \multirow[b]{2}{*}{$\begin{array}{c}\text { HBV patients who } \\
\text { developed HCC, no. }(\%)\end{array}$} & \multicolumn{2}{|c|}{ Univariate analysis } & \multicolumn{2}{|c|}{ Multivariate analysis ${ }^{\mathrm{a}}$} \\
\hline & & & $\begin{array}{c}\mathrm{HR} \\
(95 \% \mathrm{CI})\end{array}$ & P-value & $\begin{array}{c}\mathrm{HR} \\
(95 \% \mathrm{CI})\end{array}$ & P-value \\
\hline $\begin{array}{l}\text { Age (years), } \\
\text { mean (SD) }\end{array}$ & $43.61(11.75)$ & $50.97(10.36)$ & $1.07(1.05-1.08)$ & $<0.0001^{\mathrm{c}}$ & $1.05(1.03-1.07)$ & $<0.0001^{\mathrm{c}}$ \\
\hline$<43$ & $550(47.7)$ & $22(22.9)$ & 1.00 & & 1.00 & \\
\hline$\geq 43$ & $602(52.3)$ & $74(77.1)$ & $3.48(2.16-5.61)$ & $<0.0001^{\mathrm{c}}$ & $2.23(1.36-3.65)$ & $0.0014^{\mathrm{c}}$ \\
\hline \multicolumn{7}{|l|}{ Gender } \\
\hline Female & $391(33.9)$ & $15(15.6)$ & 1.00 & & 1.00 & \\
\hline Male & $761(66.1)$ & $81(84.4)$ & $2.81(1.62-4.88)$ & $0.0002^{\mathrm{c}}$ & $1.88(1.01-3.47)$ & $0.0450^{\mathrm{c}}$ \\
\hline \multicolumn{7}{|l|}{ Smoking status } \\
\hline Never & $688(59.7)$ & $35(36.5)$ & 1.00 & & 1.00 & \\
\hline Ever & $382(33.2)$ & $49(51.0)$ & $2.61(1.69-4.03)$ & $<0.0001^{\mathrm{c}}$ & $2.47(1.39-4.38)$ & $0.0021^{\mathrm{c}}$ \\
\hline Unknown & $82(7.1)$ & $12(12.5)$ & $2.84(1.47-5.47)$ & 0.0019 & $12.43(2.92-52.97)$ & 0.0007 \\
\hline \multicolumn{7}{|l|}{ Drinking status } \\
\hline Never & $646(56.1)$ & $41(42.7)$ & 1.00 & & 1.00 & \\
\hline Ever & $425(36.9)$ & $45(46.9)$ & $1.72(1.12-2.62)$ & $0.0123^{c}$ & $0.67(0.38-1.16)$ & 0.1527 \\
\hline Unknown & $81(7.0)$ & $10(10.4)$ & $1.90(0.95-3.79)$ & 0.0693 & $0.15(0.03-0.71)$ & 0.0171 \\
\hline \multicolumn{7}{|l|}{ Cirrhosis } \\
\hline No & $827(71.8)$ & $19(19.8)$ & 1.00 & & 1.00 & \\
\hline Yes & $325(28.2)$ & $77(80.2)$ & $12.25(7.41-20.25)$ & $<0.0001^{\mathrm{c}}$ & $7.62(4.53-12.83)$ & $<0.0001^{\mathrm{c}}$ \\
\hline \multicolumn{7}{|l|}{$\begin{array}{l}\text { Family history } \\
\text { of cancer }\end{array}$} \\
\hline No & $776(67.4)$ & $57(59.4)$ & 1.00 & & 1.00 & \\
\hline Yes & $376(32.6)$ & $39(40.6)$ & $1.50(1.00-2.25)$ & 0.0523 & $1.21(0.80-1.84)$ & 0.3657 \\
\hline $\begin{array}{l}\operatorname{AFP}(\mathrm{ng} / \mathrm{ml}) \\
\text { median (IQR) }\end{array}$ & $3.10(2.00-6.40)$ & $10.86(5.15-47.05)$ & $1.62(1.50-1.76)^{\mathrm{b}}$ & $<0.0001^{\mathrm{b}, \mathrm{c}}$ & $1.51(1.36-1.67)^{\mathrm{b}}$ & $<0.0001^{b, c}$ \\
\hline$<20$ & $1015(88.1)$ & $59(61.5)$ & 1.00 & & 1.00 & \\
\hline$\geq 20$ & $137(11.9)$ & $37(38.5)$ & $5.39(3.57-8.13)$ & $<0.0001^{\mathrm{c}}$ & $2.75(1.78-4.25)$ & $<0.0001^{\mathrm{c}}$ \\
\hline
\end{tabular}

HCC, hepatocellular carcinoma; SD, standard deviation; IQR, interquartile range; AFP, $\alpha$-fetoprotein; HR, hazard ratio; CI, confidence interval. ${ }^{a}$ Adjusted for age, gender, smoking status, drinking status, family history of cancer, and cirrhosis, where appropriate. ${ }^{\mathrm{b}} \mathrm{After}$ natural log transformation. ${ }^{\mathrm{C}} \mathrm{P}<0.05$.

cirrhotic patients $(\mathrm{HR}=7.62,95 \% \mathrm{CI}, 4.53-12.83)$, and patients with a high AFP value ( $\mathrm{HR}=2.75,95 \% \mathrm{CI}, 1.78-4.25)$. Although increased HCC risk was observed in ever drinkers and patients with a family history of cancer in the univariate analyses, the associations were not statistically significant after adjustment for covariates.

Association between ferritin level and HCC risk. HBV patients who developed HCC had a significantly higher ferritin level [median $188.00 \mathrm{ng} / \mathrm{ml}$, interquartile range (IQR) $119.50-299.76 \mathrm{ng} / \mathrm{ml}]$ than those who remained cancer-free (median $108.00 \mathrm{ng} / \mathrm{ml}$, IQR 53.10-204.95 ng/ml, P<0.0001). We then divided HBV patients into different risk groups according to the clinical cut-off or percentile cut-offs. As shown in Fig. 1, the cumulative HCC incidence was significantly higher in patients with a high ferritin level than in those with a low ferritin level, no matter which kind of cut-offs were used (all log-rank $\mathrm{P}<0.0001)$. Compared to the patients with a ferritin level less than $200 \mathrm{ng} / \mathrm{ml}$, the patients with a high ferritin level $(\geq 200 \mathrm{ng} / \mathrm{ml}$ ) had 2.43-fold increased risk of HCC ( $\mathrm{HR}=2.43$, 95\% CI, 1.63-3.63, Table II). The association was still significant after adjusting for age, gender, smoking status, drinking status, and family history of cancer $(\mathrm{HR}=1.76,95 \% \mathrm{CI}, 1.16-2.65)$ and became borderline significant when cirrhosis and AFP were further added to multivariate adjustment $(\mathrm{HR}=1.45$, 95\% CI, 0.96-2.19). When patients were categorized according to median/tertile/quartile cutoffs, the association between ferritin and HCC risk was consistently observed in univariate and multivariate analyses (Table II). Moreover, a trend of increasing HRs along with elevated ferritin levels was noted ( $\mathrm{P}$ for trend $<0.0001$ in univariate analyses and $<0.01$ after multivariate adjustment, Table II).

Prediction performance of ferritin combined with AFP. AFP is a commonly used tumor marker in HCC diagnosis, although with a non-optimal discrimination accuracy (17). We 

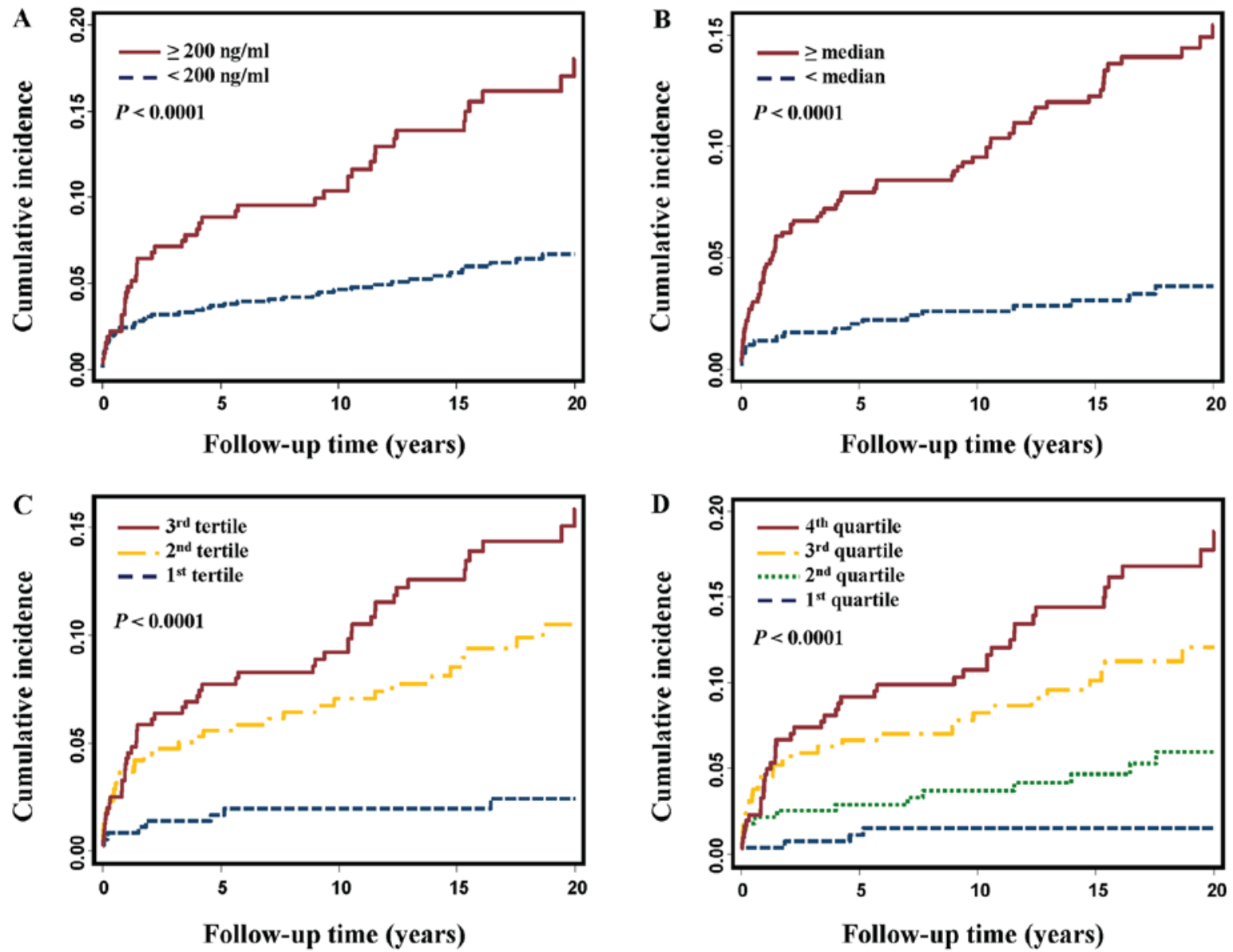

Figure 1. Cumulative incidence of HBV-related HCC. The cumulative incidence of HCC was plotted using the Nelson-Aalen method by analyzing Ferritin as a categorical variable by clinical cut-off of (A) $200 \mathrm{ng} / \mathrm{ml}$, (B) median, (C) tertile, and (D) quartile cut-offs. HBV, hepatitis B virus; HCC, hepatocellular carcinoma.

then investigated whether incorporating ferritin into the AFP prediction model could improve the performance of predicting HCC. The results showed that compared to the performance in the model with AFP values, the prediction performance significantly increased in the model in combination of ferritin and AFP levels (AUC from 0.74 to $0.77, \mathrm{P}=0.003$; Fig. 2).

Time-dependent effect and dynamic change of ferritin level. Time-dependent effect of ferritin level on HCC risk was assessed using the flexible parametric model. As shown in Fig. 3A, after the initial visit, HCC risk significantly increased in the first 5 years, reached a peak at approximately the fifth year, and kept stable after 10 years. To evaluate dynamic change of ferritin, we also selected a sub-cohort of 461 patients with 4309 detections of ferritin at both baseline and follow-up visits, and depicted the longitudinal trend of average ferritin values by fitting a smoothing spline over time (Fig. 3B). The average ferritin level in HBV patients who developed HCC $(n=50)$ was persistently higher than in those remaining cancer-free $(\mathrm{n}=411)$.

Stratified and joint effects of ferritin level on HCC risk. We stratified the main effect analysis according to patients' characteristics. In the univariate analyses, the association of ferritin level with HCC risk was significant in both strata divided by age, gender, drinking status, and family history of cancer, and only evident in ever smokers $(\mathrm{P}=0.0233)$, non-cirrhotic patients

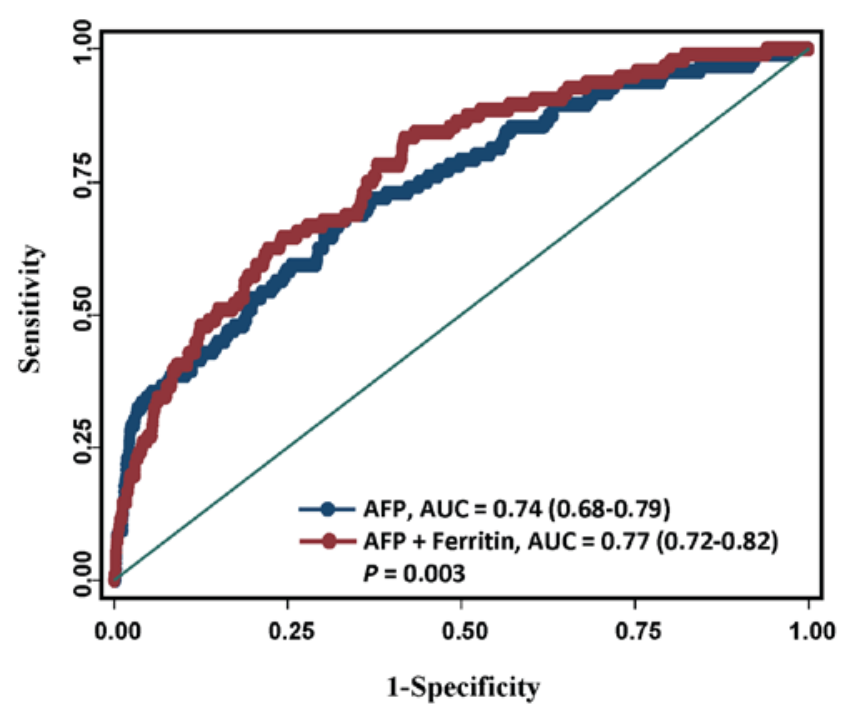

Figure 2. Receiver operating characteristic curves for assessment of prediction performance of HCC. The AUC was compared between the AFP models without and with ferritin levels. AUC, area under the curve; HCC, hepatocellular carcinoma.

( $\mathrm{P}=0.0155)$, and patients with a AFP value less than $20 \mathrm{ng} / \mathrm{ml}$ ( $\mathrm{P}=0.0004$; Table III). After multivariate adjustment, we only observed a borderline significant association in older patients $(\mathrm{P}=0.0940)$ and patients with a low AFP value $(\mathrm{P}=0.0837)$. 


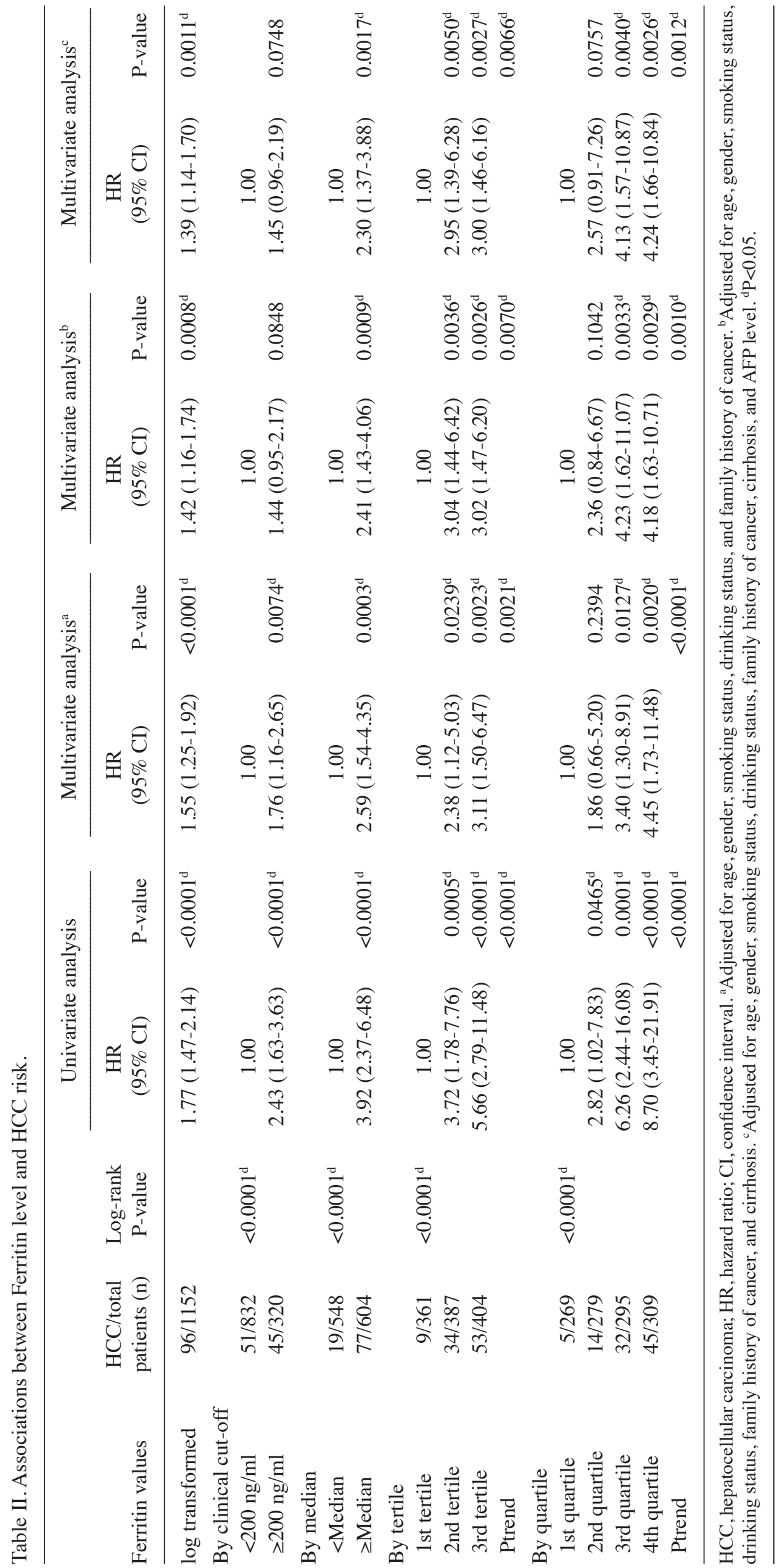



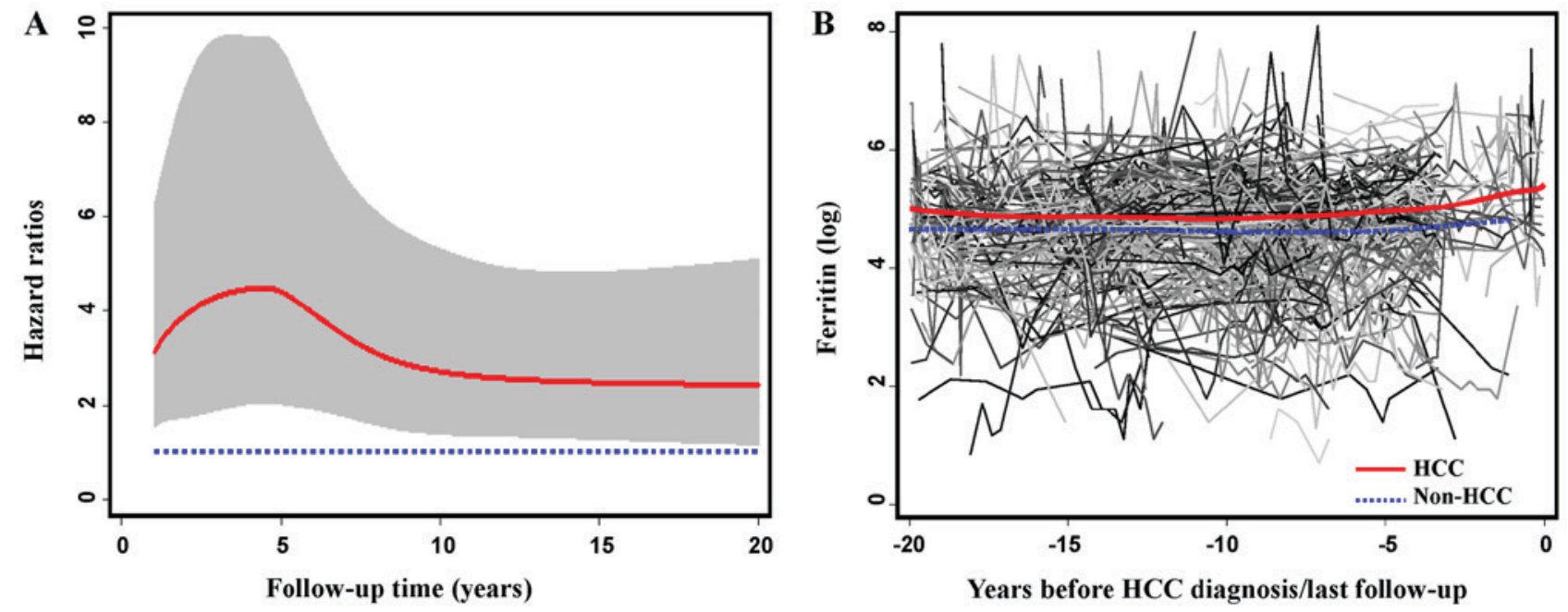

Figure 3. Time-dependent effect and dynamic change of Ferritin level. (A) Time-dependent effect of Ferritin level on HCC risk, red solid line represents HR, shaded area shows 95\% confidence interval, blue dash line indicates a reference HR of 1; (B) Longitudinal trend of average Ferritin level in the patients who developed HCC (red solid line) and those who were cancer-free (blue dash line), grey lines indicate individual profiles for all subjects. HR, hazard ratio; HCC, hepatocellular carcinoma.

Because the clinical normal range differed between females and males (13) and because we detected a joint effect between ferritin level and gender on HCC risk (P for interaction $=0.0087$ ), we further evaluated gender-specific effect and compared the cumulative incidence in females and males. As expected, ferritin levels were much higher in males than in females (median $160 \mathrm{ng} / \mathrm{ml}$ vs. $50.40 \mathrm{ng} / \mathrm{ml}$, $\mathrm{P}<0.0001)$. Both female and male HBV patients who developed HCC had significantly higher ferritin levels compared to those who were still cancer-free (134 vs. $48.95 \mathrm{ng} / \mathrm{ml}$, $\mathrm{P}=0.0003$ in females; 188.90 vs. $154.80 \mathrm{ng} / \mathrm{ml}, \mathrm{P}=0.0025$ in males, Table IV). The significantly increased cumulative incidence was observed in both female and male patients with a high ferritin level when gender-specific clinical cut-offs were used (Fig. 4A and B).

We also detected a joint effect between ferritin and AFP level on HCC risk (P for interaction=0.0036). We then compared ferritin level and cumulative incidence in patients with a low or high AFP value. We noticed that in patients with a low AFP value $(<20 \mathrm{ng} / \mathrm{ml})$, the HBV patients who developed HCC had a significantly higher level of ferritin than those who remained cancer-free (178 vs. $103.25 \mathrm{ng} / \mathrm{ml}$, $\mathrm{P}<0.0001$; Table V); however, in patients with a high AFP value $(\geq 20 \mathrm{ng} / \mathrm{ml}$ ), the ferritin level in the HCC patients was slightly lower than that in the non-HCC patients ( 230 vs. $283 \mathrm{ng} / \mathrm{ml}$ ), but the difference was not statistically significant. Similarly, significantly increased cumulative incidence of HCC with elevated ferritin level was observed in patients with a low AFP value (Fig. 4C and D).

\section{Discussion}

Serum ferritin is a widely available and easily measured biochemical parameter in clinics. Previous studies detected a higher level of ferritin in HCC patients; however, these studies did not reveal whether there was a causal association between serum ferritin level and hepatocarcinogenesis in HBV infected patients. In the current study based on a well-established prospective cohort, we demonstrated that baseline ferritin level could independently predict the risk of HBV-related HCC, especially in the first 10 years of follow-up. Moreover, the association between ferritin level and HCC risk was noted in both males and females, and was prominent in patients with a low AFP value.

The tumor enhancing effect of iron has been well documented $(18,19)$. Accumulating evidence has indicated that an increased iron level predisposes a patient to infection, induces oxidative stress, modifies the immune system, and facilitates the growth of tumor cells $(2,5,20,21)$. Furthermore, antitumor effect of iron depletion by deferoxamine was observed in nude mice bearing human HCC (22). As an iron storage protein, ferritin makes iron available for critical cellular processes while protecting lipids, DNA, and proteins from the potentially toxic effects of iron (23). Serum ferritin is an inexpensive biomarker in identifying clinically significant iron overload (23). Elevated ferritin concentrations could also be observed in inflammatory processes, autoimmune diseases, neurodegenerative, metabolic syndrome, and malignant diseases (23). In addition to the amount synthesized by tumor cells, ferritin is also released into the circulation by damaged hepatocytes in liver diseases. Cirrhosis is almost always present when HCC is diagnosed and progressive hepatic iron loading develops in one-third of patients with long-standing liver cirrhosis (21); however, previous studies failed to clarify whether ferritin is an independent predictor of HCC or acts indirectly through coexisting cirrhosis. A recent animal model of dietary iron overload reported iron-free preneoplastic nodules and HCC developed in the absence of fibrosis or cirrhosis, suggesting that ionic iron may also be directly hepatocarcinogenic $(24,25)$. In the current study, which was conducted in chronic HBV infected patients, we demonstrated the association between ferritin and HCC risk that was independent of other liver diseases including cirrhosis (Table II).

It is well known that the average ferritin level in males is much higher than in females, thus a gender-specific cut-off is 
Table III. Associations between Ferritin level and HCC risk stratified by patients' characteristics.

\begin{tabular}{|c|c|c|c|c|c|c|}
\hline \multirow[b]{2}{*}{ Variable } & \multirow{2}{*}{$\begin{array}{l}\text { Ferritin values } \\
\qquad(\mathrm{ng} / \mathrm{ml})\end{array}$} & \multirow{2}{*}{$\begin{array}{l}\text { HCC/total } \\
\text { patients }(\mathrm{N})\end{array}$} & \multicolumn{2}{|c|}{ Univariate analysis } & \multicolumn{2}{|c|}{ Multivariate analysis $^{\mathrm{a}}$} \\
\hline & & & HR $(95 \% \mathrm{CI})$ & P-value & $\mathrm{HR}(95 \% \mathrm{CI})$ & P-value \\
\hline \multicolumn{7}{|l|}{ Age (years) } \\
\hline \multirow[t]{2}{*}{$<43$} & $<200$ & $12 / 416$ & 1 & & 1 & \\
\hline & $\geq 200$ & $10 / 134$ & $2.74(1.18-6.33)$ & $0.0188^{\mathrm{b}}$ & $1.70(0.70-4.17)$ & 0.2430 \\
\hline \multirow{2}{*}{$\geq 43$} & $<200$ & $39 / 416$ & 1 & & 1 & \\
\hline & $\geq 200$ & $35 / 186$ & $2.11(1.34-3.33)$ & $0.0013^{\mathrm{b}}$ & $1.50(0.93-2.40)$ & 0.0940 \\
\hline $\mathrm{P}$ for interaction & & & & 0.6144 & & 0.9970 \\
\hline \multicolumn{7}{|l|}{ Gender } \\
\hline \multirow[t]{2}{*}{ Female } & $<200$ & $9 / 353$ & 1 & & 1 & \\
\hline & $\geq 200$ & $6 / 38$ & $7.29(2.59-20.51)$ & $0.0002^{\mathrm{b}}$ & $1.25(0.29-5.45)$ & 0.7695 \\
\hline \multirow[t]{2}{*}{ Male } & $<200$ & $42 / 479$ & 1 & & 1 & \\
\hline & $\geq 200$ & $39 / 282$ & $1.64(1.06-2.53)$ & $0.0269^{b}$ & $1.45(0.93-2.27)$ & 0.1040 \\
\hline $\mathrm{P}$ for interaction & & & & $0.0087^{\mathrm{b}}$ & & 0.9203 \\
\hline \multicolumn{7}{|l|}{ Smoking status } \\
\hline \multirow[t]{2}{*}{ Never } & $<200$ & $23 / 533$ & 1 & & 1 & \\
\hline & $\geq 200$ & $12 / 155$ & $1.88(0.94-3.78)$ & 0.0758 & $1.12(0.54-2.33)$ & 0.7679 \\
\hline \multirow[t]{2}{*}{ Ever } & $<200$ & $23 / 236$ & 1 & & 1 & \\
\hline & $\geq 200$ & $26 / 146$ & $1.92(1.09-3.36)$ & $0.0233^{\mathrm{b}}$ & $1.48(0.81-2.71)$ & 0.2064 \\
\hline $\mathrm{P}$ for interaction & & & & 0.9982 & & 0.5633 \\
\hline \multicolumn{7}{|l|}{ Drinking status } \\
\hline \multirow[t]{2}{*}{ Never } & $<200$ & $26 / 505$ & 1 & & 1 & \\
\hline & $\geq 200$ & $15 / 141$ & $2.23(1.18-4.21)$ & $0.0136^{\mathrm{b}}$ & $1.14(0.58-2.24)$ & 0.7121 \\
\hline \multirow[t]{2}{*}{ Ever } & $<200$ & $21 / 264$ & 1 & & 1 & \\
\hline & $\geq 200$ & $24 / 161$ & $1.93(1.08-3.47)$ & $0.0275^{\mathrm{b}}$ & $1.41(0.76-2.64)$ & 0.2774 \\
\hline$P$ for interaction & & & & 0.7706 & & 0.8010 \\
\hline \multicolumn{7}{|l|}{ Cirrhosis } \\
\hline \multirow[t]{2}{*}{ No } & $<200$ & $10 / 639$ & 1 & & 1 & \\
\hline & $\geq 200$ & $9 / 196$ & $3.04(1.24-7.49)$ & $0.0155^{\mathrm{b}}$ & $1.27(0.46-3.52)$ & 0.6515 \\
\hline \multirow[t]{2}{*}{ Yes } & $<200$ & $41 / 193$ & 1 & & 1 & \\
\hline & $\geq 200$ & $36 / 124$ & $1.43(0.91-2.24)$ & 0.1176 & $1.27(0.80-2.03)$ & 0.3078 \\
\hline$P$ for interaction & & & & 0.1410 & & 0.5747 \\
\hline \multicolumn{7}{|c|}{ Family history of cancer } \\
\hline \multirow[t]{2}{*}{ No } & $<200$ & $30 / 575$ & 1 & & 1 & \\
\hline & $\geq 200$ & $27 / 201$ & $2.70(1.61-4.54)$ & $0.0002^{\mathrm{b}}$ & $1.53(0.89-2.65)$ & 0.1263 \\
\hline \multirow[t]{2}{*}{ Yes } & $<200$ & $21 / 257$ & 1 & & 1 & \\
\hline & $\geq 200$ & $18 / 119$ & $1.95(1.04-3.67)$ & $0.0375^{\mathrm{b}}$ & $1.25(0.63-2.49)$ & 0.5233 \\
\hline $\mathrm{P}$ for interaction & & & & 0.4255 & & 0.8123 \\
\hline \multicolumn{7}{|l|}{ AFP (ng/ml) } \\
\hline$<20$ & $<200$ & $34 / 778$ & 1 & & 1 & \\
\hline & $\geq 200$ & $25 / 237$ & $2.55(1.52-4.28)$ & $0.0004^{\mathrm{b}}$ & $1.61(0.94-2.77)$ & 0.0837 \\
\hline$\geq 20$ & $<200$ & $17 / 54$ & 1 & & 1 & \\
\hline & $\geq 200$ & $20 / 83$ & $0.72(0.38-1.38)$ & 0.3194 & $0.75(0.38-1.46)$ & 0.3954 \\
\hline $\mathrm{P}$ for interaction & & & & $0.0036^{\mathrm{b}}$ & & $0.0583^{b}$ \\
\hline
\end{tabular}

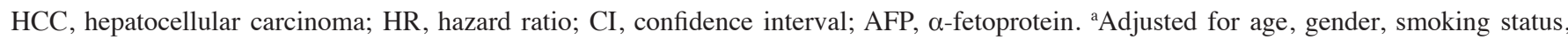
drinking status, family history of cancer, cirrhosis, and AFP level, where appropriate. ${ }^{b} \mathrm{P}<0.05$.

often suggested in clinics $(2,13,26)$. A recent study reported an independent predicting value of serum ferritin in the development of HCV-related HCC, and this association was only observed in male patients (27). Previous studies 
Table IV. Ferritin levels by gender.

\begin{tabular}{|c|c|c|c|c|c|c|}
\hline \multirow[b]{2}{*}{ Variables } & \multicolumn{3}{|c|}{ Females $(n=391)$} & \multicolumn{3}{|c|}{ Males $(n=761)$} \\
\hline & Non-HCC $(n=376)$ & $\operatorname{HCC}(n=15)$ & P-value & Non-HCC $(n=680)$ & $\operatorname{HCC}(n=81)$ & $\mathrm{P}$-value \\
\hline $\begin{array}{l}\text { Ferritin }(\mathrm{ng} / \mathrm{ml}) \text {, } \\
\text { median (IQR) }\end{array}$ & $\begin{array}{c}48.95 \\
(25.60-96.95)\end{array}$ & $\begin{array}{c}134.00 \\
(96.00-446.00)\end{array}$ & $0.0003^{\mathrm{a}}$ & $\begin{array}{c}154.80 \\
(95.00-256.35)\end{array}$ & $\begin{array}{c}188.90 \\
(124.00-296.52)\end{array}$ & $0.0025^{\mathrm{a}}$ \\
\hline
\end{tabular}

HCC, hepatocellular carcinoma; IQR, interquartile range. ${ }^{\mathrm{a}} \mathrm{P}<0.05$.

Table V. Ferritin levels by AFP level.

\begin{tabular}{|c|c|c|c|c|c|c|}
\hline \multirow[b]{2}{*}{ Variables } & \multicolumn{3}{|c|}{ AFP $<20 \mathrm{ng} / \mathrm{ml}(\mathrm{n}=1,015)$} & \multicolumn{3}{|c|}{$\mathrm{AFP} \geq 20 \mathrm{ng} / \mathrm{ml}(\mathrm{n}=137)$} \\
\hline & Non-HCC $(n=956)$ & $\operatorname{HCC}(n=59)$ & P-value & Non-HCC $(n=100)$ & $\operatorname{HCC}(n=37)$ & P-value \\
\hline $\begin{array}{l}\text { Ferritin }(\mathrm{ng} / \mathrm{ml}) \text {, } \\
\text { median }(\mathrm{IQR})\end{array}$ & $\begin{array}{c}103.25 \\
(50.00-187.25)\end{array}$ & $\begin{array}{c}178.00 \\
(119.00-253.30)\end{array}$ & $<0.0001^{\mathrm{a}}$ & $\begin{array}{c}283.00 \\
(123.20-619.00)\end{array}$ & $\begin{array}{c}230.00 \\
(120.00-495.00)\end{array}$ & $0.38750^{\mathrm{a}}$ \\
\hline
\end{tabular}

AFP, $\alpha$-fetoprotein; HCC, hepatocellular carcinoma; IQR, interquartile range. ${ }^{\mathrm{P}}<<0.05$.

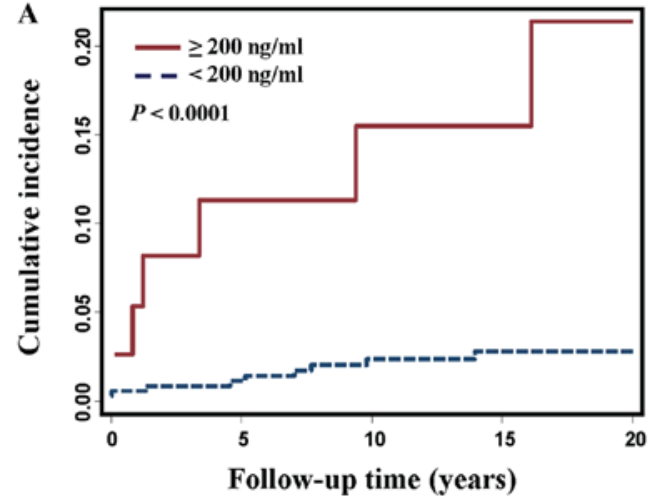

Females

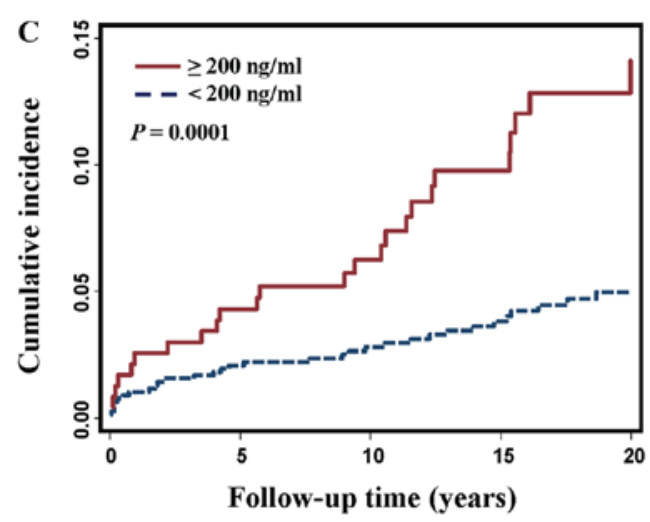

Low AFP

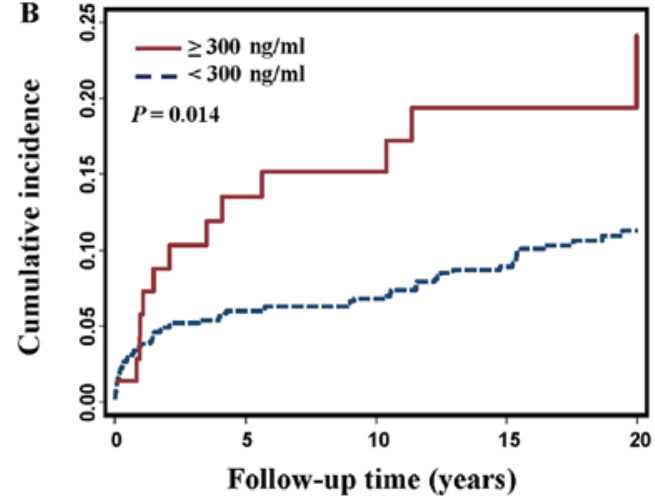

Males

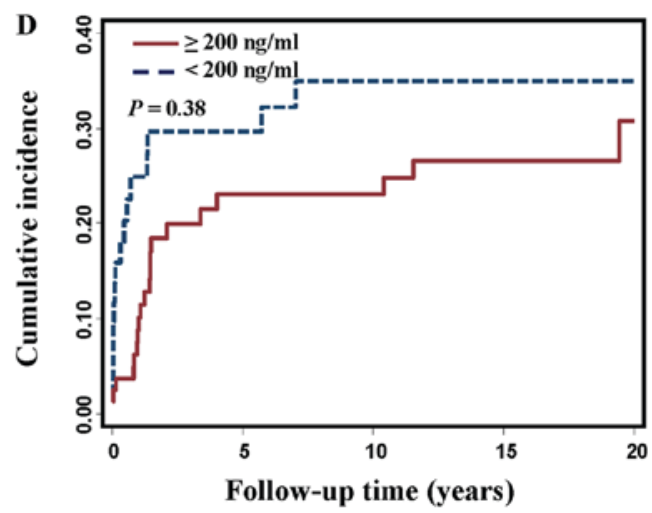

High AFP

Figure 4. Cumulative incidence of HBV-related HCC stratified by gender and AFP value. The cumulative incidence of HCC was compared between patients with a low and high Ferritin level in (A) females, (B) males, (C) patients with a low AFP value, or (D) patients with a high AFP value. HBV, hepatitis B virus; HCC, hepatocellular carcinoma.

conducted in HBV patients also identified increased HCC risk in male patients with a high level of ferritin. But these studies were either conducted in males alone (10) or involved a small number of female patients (5). Our present study with 761 males and 391 females demonstrated that the association between ferritin level and HCC risk was observed in both 
males and females, even when males or females were stratified into different risk groups by a gender-specific cut-off of ferritin (Fig. 3). It is unclear whether the inconsistent finding of ferritin effect on HBV patients compared to HCV patients signifies that hepatocarcinogenesis differs in patients with different disease etiologies. It would be worthwhile to conduct additional studies to validate our finding and clarify gender-specific effects.

AFP is a widely recognized tumor marker for the diagnosis of HCC. However, there have been false-positive results for HCC detection, as elevated AFP also occurs in chronic liver disease and other malignancies than HCC; false-negative results were reported as well, as not all HCCs secrete AFP $(17,28,29)$. Our results showed that the performance of HCC prediction significantly improved after incorporating ferritin into the AFP prediction model (Fig. 2), suggesting a complementary role of ferritin in prediction of HCC development. Adult hepatocytes re-express AFP mainly through mechanisms including hepatocyte regeneration, and oxidative stress induced DNA damage (30). Noritake et al (31) reported that iron reduction by therapeutic phlebotomy could reduce the serum AFP in HCV patients, which probably mediated by the amelioration of enhanced hepatic iron-mediated oxidative stress. Although the biological mechanisms underlying the combined effect of AFP and Ferritin on HCC development are still needed to be further investigated, the present findings in our study demonstrated the potential of using these two serum markers for the joint diagnosis of HCC. Nevertheless, it should be noted that after adding ferritin to the model, the diagnostic power was still moderate, albeit slightly increased. Therefore, it would be worthwhile to study whether a model including more risk factors, as well as novel molecular markers could further improve the diagnostic performance. In addition, in the stratification analyses, we found that the association of ferritin level with HCC risk was more evident in patients with a AFP value less than $20 \mathrm{ng} / \mathrm{ml}$. Our result was consistent with the finding of Zhou et al (32) who suggested that serum ferritin estimation may be helpful in detection of $\mathrm{HCC}$ without elevated AFP, and further supported the complementary information from ferritin to AFP-based HCC diagnosis. Nevertheless, due to decreased sample size in each stratum, especially in the patients with a high level of AFP, it should be cautious when we explained the detected interaction between ferritin and AFP, as well as, the failure in identifying significant difference in ferritin levels between HCC and non-HCC patients when the comparison was conducted in those with elevated AFP.

Our study was based on a large-scale and homogenous cohort of Korean patients with chronic HBV infection, so the confounding effects of patient ethnicity and disease etiology have been eliminated. We only included patients who were followed for at least 1 year, and during which time HCC did not develop (1-year exclusion window). This criterion ensured that all of the patients were free of HCC at study entry. Therefore, the increased baseline ferritin level was more likely linked to the development of HCC rather than the release from existing tumor cells. In order to minimize the confounding effect of any patient who had undiagnosed $\mathrm{HCC}$ at baseline sample collection, we further restricted the analyses to a sub-cohort of patients with a 2-year exclusion window, that is, only included the patients who were followed for at least 2 years and had not developed HCC within these 2 years. The result from this sub-cohort analysis $(\mathrm{HR}=2.76,95 \% \mathrm{CI}, 1.60-4.78$; adjusted $\mathrm{HR}=2.23,95 \% \mathrm{CI}, 1.25-3.97$ ) was very similar to that from the analysis based on the population with 1-year exclusion window $(\mathrm{HR}=2.43,95 \% \mathrm{CI}, 1.63-3.63$; adjusted $\mathrm{HR}=1.76$, $95 \%$ CI, 1.16-2.65, Table II), which substantiates the robustness of our findings. Furthermore, ferritin is a non-invasive, cost-effective, and easily obtained biomarker in clinics so that it can be real-time detected and repetitively monitored during follow-up.

Our study also has limitations. First, liver biopsy is the gold standard for quantifying iron, while serum ferritin levels do not always accurately reflect tissue iron $(2,23,33)$. However, in the current study, very few patients had baseline serum iron concentration or transferrin saturation, and none of the patients had detection of tissue iron, so we are unable to accurately assess the relationship between ferritin, iron, and the development of HBV-related HCC. Second, some important covariates, such as HBV DNA loading and body mass index, which were reported to be associated with HCC risk and/or correlate with serum ferritin level $(12,34)$, were not included in multivariate analyses due to a high percentage of missing values. Future studies with more complete data could be designed to evaluate the confounding effects from these covariates. Third, this study was based on the data collected in a single institute. Prospective studies from independent external cohorts are required to validate our results. Moreover, the generalizability of our findings to patients of other ethnicities or disease etiologies is required to be assessed.

In short, our large scale cohort study indicated that serum ferritin could prospectively predict hepatocarcinogenesis in chronic HBV infected patients. Given ferritin is a non-invasive blood-born maker which can be easily obtained from routine laboratory test and be real-time monitored during follow-up, the clinical significance of ferritin in early diagnosis and effective management of HCC should not be overlooked.

\section{Acknowledgements}

The authors would like to thank Jennifer Wilson (Thomas Jefferson University, Philadelphia, PA, USA) for editorial assistance.

\section{Funding}

This study was supported by the National Natural Science Foundation of China (grant no. 81402328).

\section{Availability of data and materials}

All data generated or analyzed during this study are included in this published article.

\section{Authors' contributions}

KT conceived the study and designed the project. ZB and $\mathrm{HWH}$ designed the experiments. ZB, ZY, CY and YW performed the experiments. ZB, WF, CW and SW analyzed the data. KT, $\mathrm{CW}, \mathrm{ZB}$ and $\mathrm{HWH}$ interpreted the data and wrote the article. All authors have read and approved the article for publication. 


\section{Ethics approval and consent to participate}

The study was approved by the Institutional Review Board of Thomas Jefferson University. Written informed consent was obtained from all individual participants included in the study.

\section{Consent for publication}

Written informed consent was obtained from all individual participants included in the study.

\section{Competing interests}

The authors declare that they have no competing interests.

\section{References}

1. Singal AG and El-Serag HB: Hepatocellular carcinoma from epidemiology to prevention: Translating knowledge into practice. Clin Gastroenterol Hepatol 13: 2140-2151, 2015.

2. Fleming RE and Ponka P: Iron overload in human disease. $\mathrm{N}$ Engl J Med 366: 348-359, 2012.

3. Hann HW, Stahlhut MW and Hann CL: Effect of iron and desferoxamine on cell growth and in vitro ferritin synthesis in human hepatoma cell lines. Hepatology 11: 566-569, 1990.

4. Schwarzenbach H, Müller V, Milde-Langosch K, Steinbach B and Pantel K: Evaluation of cell-free tumour DNA and RNA in patients with breast cancer and benign breast disease. Mol Biosyst 7: 2848-2854, 2011.

5. Hann HW, Kim CY, London WT and Blumberg BS: Increased serum ferritin in chronic liver disease: A risk factor for primary hepatocellular carcinoma. Int J Cancer 43: 376-379, 1989.

6. KowdleyKV,BeltP,WilsonLA, YehMM,Neuschwander-TetriBA Chalasani N, Sanyal AJ and Nelson JE; NASH Clinical Research Network: Serum ferritin is an independent predictor of histologic severity and advanced fibrosis in patients with nonalcoholic fatty liver disease. Hepatology 55: 77-85, 2012.

7. Nakano S, Kumada T, Sugiyama K, Watahiki H and Takeda I: Clinical significance of serum ferritin determination for hepatocellular carcinoma. Am J Gastroenterol 79: 623-627, 1984

8. Simonetti RG, Craxi A, Dardanonì G, Lanzarone F, Barbaria F, Cottone $\mathrm{M}$ and Pagliaro L: The clinical value of serum ferritin in hepatocellular carcinoma. Hepatogastroenterology 32: 276-278, 1985.

9. Tatsuta M, Yamamura H, Iishi H, Kasugai H and Okuda S: Value of serum alpha-fetoprotein and ferritin in the diagnosis of hepatocellular carcinoma. Oncology 43: 306-310, 1986.

10. Stevens RG, Beasley RP and Blumberg BS: Iron-binding proteins and risk of cancer in Taiwan. J Natl Cancer Inst 76: 605-610, 1986

11. Hann HW, Fu X, Myers RE, Hann RS, Wan S, Kim SH, Au N, Xing $J$ and Yang $\mathrm{H}$ : Predictive value of alpha-fetoprotein in the long-term risk of developing hepatocellular carcinoma in patients with hepatitis B virus infection-results from a clinic-based longitudinal cohort. Eur J Cancer 48: 2319-2327, 2012.

12. Fu X, Wan S, Hann HW, Myers RE, Hann RS, Au J, Chen B, Xing J and Yang H: Relative telomere length: A novel non-invasive biomarker for the risk of non-cirrhotic hepatocellular carcinoma in patients with chronic hepatitis B infection. Eur J Cancer 48: 1014-1022, 2012.

13. Adams P: Management of elevated serum ferritin levels. Gastroenterol Hepatol (N Y) 4: 333-334, 2008.

14. Andersen PK, Geskus RB, de Witte T and Putter H: Competing risks in epidemiology: Possibilities and pitfalls. Int $\mathrm{J}$ Epidemiol 41: 861-870, 2012.
15. Royston $\mathrm{P}$ and Parmar MK: Flexible parametric proportional-hazards and proportional-odds models for censored survival data, with application to prognostic modelling and estimation of treatment effects. Stat Med 21: 2175-2197, 2002.

16. Hann HW, Wan S, Lai Y, Hann RS, Myers RE, Patel F, Zhang K, Ye Z, Wang $\mathrm{C}$ and Yang $\mathrm{H}$ : Aspartate aminotransferase to platelet ratio index as a prospective predictor of hepatocellular carcinoma risk in patients with chronic hepatitis B virus infection. J Gastroenterol Hepatol 30: 131-138, 2015.

17. Chen CJ and Lee MH: Early diagnosis of hepatocellular carcinoma by multiple microRNAs: Validity, efficacy, and cost-effectiveness. J Clin Oncol 29: 4745-4747, 2011.

18. Hann HW, Stahlhut MW and Menduke H: Iron enhances tumor growth. Observation on spontaneous mammary tumors in mice. Cancer 68: 2407-2410, 1991.

19. Hann HW, Stahlhut MW and Blumberg BS: Iron nutrition and tumor growth: Decreased tumor growth in iron-deficient mice. Cancer Res 48: 4168-4170, 1988.

20. Kew MC: Hepatic iron overload and hepatocellular carcinoma. Liver Cancer 3: 31-40, 2014.

21. Deugnier Y and Turlin B: Iron and hepatocellular carcinoma. J Gastroenterol Hepatol 16: 491-494, 2001.

22. Hann HW, Stahlhut MW, Rubin R and Maddrey WC: Antitumor effect of deferoxamine on human hepatocellular carcinoma growing in athymic nude mice. Cancer 70 : 2051-2056, 1992.

23. Knovich MA, Storey JA, Coffman LG, Torti SV and Torti FM: Ferritin for the clinician. Blood Rev 23: 95-104, 2009.

24. Asare GA, Paterson AC, Kew MC, Khan S and Mossanda KS: Iron-free neoplastic nodules and hepatocellular carcinoma without cirrhosis in Wistar rats fed a diet high in iron. J Pathol 208: 82-90, 2006.

25. Asare GA, Mossanda KS, Kew MC, Paterson AC, Kahler-Venter CP and Siziba K: Hepatocellular carcinoma caused by iron overload: A possible mechanism of direct hepatocarcinogenicity. Toxicology 219: 41-52, 2006.

26. Zacharski LR, Ornstein DL, Woloshin S and Schwartz LM: Association of age, sex, and race with body iron stores in adults: Analysis of NHANES III data. Am Heart J 140: 98-104, 2000.

27. Uchino K, Tateishi R, Fujiwara N, Minami T, Sato M, Enooku K, Nakagawa H, Asaoka Y, Kondo Y, Yoshida H, et al: Impact of serum ferritin level on hepatocarcinogenesis in chronic hepatitis C patients. Hepatol Res 46: 259-268, 2016.

28. Giordano $\mathrm{S}$ and Columbano A: MicroRNAs: New tools for diagnosis, prognosis, and therapy in hepatocellular carcinoma? Hepatology 57: 840-847, 2013.

29. Chang TS, Wu YC, Tung SY, Wei KL, Hsieh YY, Huang HC, Chen WM, Shen $\mathrm{CH}$, Lu CH, Wu CS, et al: Alpha-fetoprotein measurement benefits hepatocellular carcinoma surveillance in patients with cirrhosis. Am J Gastroenterol 110: 836-845, 2015.

30. Chen Y, Zhao Y, Feng L, Zhang J, Zhang J and Feng G: Association between alpha-fetoprotein and metabolic syndrome in a Chinese asymptomatic population: A cross-sectional study. Lipids Health Dis 15: 85, 2016.

31. Noritake H, Kobayashi Y, Ooba Y, Kitsugi K, Shimoyama S, Yamazaki S, Chida T, Watanabe S, Kawata K and Suda T: Improved serum alpha-fetoprotein levels after iron reduction therapy in HCV patients. ISRN Hepatol 2014: 875140, 2014.

32. Zhou XD, Stahlhut MW, Hann HL and London WT: Serum ferritin in hepatocellular carcinoma. Hepatogastroenterology 35: $1-4,1988$

33. Deugnier Y and Turlin B: Pathology of hepatic iron overload. Semin Liver Dis 31: 260-271, 2011

34. McKinnon EJ, Rossi E, Beilby JP, Trinder D and Olynyk JK: Factors that affect serum levels of ferritin in Australian adults and implications for follow-up. Clin Gastroenterol Hepatol 12: 101-108.e4, 2014.

This work is licensed under a Creative Commons Attribution-NonCommercial-NoDerivatives 4.0 International (CC BY-NC-ND 4.0) License. 